\title{
Road Traffic Accidents: A Wild Life Exterminator
}

Hadiseh Kavandi ${ }^{1}$, Samad EJ Golzari ${ }^{2 *}$

1. Tabriz University of Medical Sciences, Tabriz, Iran

2. Drug Applied Research Center, Tabriz University of Medical Sciences, Tabriz, Iran

Once commonly traced in various parts of Southwest Asia, the Iranian cheetah (Acinonyx jubatus venaticus), a disparagingly endangered cheetah subspecies, seems to have been driven to extinction. Restricted to its only remained appropriate habitat, The Iranian cheetah has barely survived in Iran's Dasht-e Kavir plateau. Throughout the 1970s, about 200 cheetahs were estimated to live in seven protected areas in Iran (1). Nevertheless, the figures dramatically declined to 50 and 60 individuals in 2005-2006. Over ten years, Iranian researchers captured images of 76 individual cheetahs using 80 camera traps implanted throughout the Dasht-e Kavir plateau
(2). Disappointingly in 2011, camera traps captured only 20 individuals in the protected areas $(2,3)$. What adds insult to the injury is knowing the fact that two-thirds of cheetah deaths in 2012-2013 were due to road accidents (4).

Beside the human fatalities and injuries, road traffic accidents remain as serious threats for wildlife. Although numerous measures are taken to hinder the extinction of this subspecies, efforts should be concentrated on long-term planning at both national and international levels to raise awareness and promote willingness to address this ongoing yet controllable damage.

\section{References}

1. Asadi, H. (1997). The environmental limitations and future of the Asiatic cheetah in Iran. Unpublished project progress report, IUCN Iran.

http://www.catsg.org/cheetah/05_library/5_3_publications/A/Asadi_1997_Environmental_limitations_and_future_of _Asiatic_cheetah_in_Iran.pdf (Last accessed 3/6/2015)

2. Khosravifard, Sam (29 March 2013). "How Many Asiatic Cheetahs Roam across Iran?". Scientific American. http://blogs.scientificamerican.com/guest-blog/2013/03/29/how-many-asiatic-cheetahs-roam-across-iran/ (Last accessed 3/6/2015)

\section{Corresponding author:}

Samad EJ Golzari, MD

Drug Applied Research Center, Tabriz University of Medical Sciences, Golgasht St. 5166614756 Tabriz, Iran Phone: +989141151894 E-mail: golzaris@tbzmed.ac.ir

Receive date: 2015-06-05| Accept date: 2015-06-25| Publish date: 2015-08-04

DOI: 10.7575/aiac.abcmed.15.03.04.01

\section{A I}


3. "Just 20 individual cheetahs identified in Iran so far, including 6 surviving females". Wildlife Extra. March 2013. http://www.wildlifeextra.com/go/news/iran-cheetah-population013.html\#cr. (Last accessed 3/6/2015)

4. "Camera traps capture 4 new Asiatic Cheetahs in Iran". MNA. http://en.mehrnews.com/detail/News/105252. (Last accessed 3/6/2015) 